\title{
Does hallux valgus impair physical function?
}

Akinobu Nishimura ${ }^{1,2^{*}}$ (D, Naoya Ito ${ }^{1}$, Shigeto Nakazora ${ }^{3}$, Ko Kato ${ }^{3}$, Toru Ogura ${ }^{4}$ and Akihiro Sudo ${ }^{1}$

\begin{abstract}
Background: The relationships between radiographic hallux valgus (HV) and various physical functions independent of knee osteoarthritis (KOA) were examined among residents of a mountain village in Japan.

Methods: Study participants were recruited from mountain village residents aged $\geq 50$ years. Participants' height, weight, and body mass index (BMI) were measured, and baseline data, including age, sex, and foot pain, were obtained using interviews and questionnaires. Radiography of the feet and knees was performed to assess the presence of HV $\left(\mathrm{HV}\right.$ angle $\geq 20^{\circ}$ ) and KOA (Kellgren-Lawrence grade $\left.\geq \mathrm{II}\right)$. Grip strength, 6-m walk at usual and maximum speeds, single-leg stance time, and stand up from a chair time were evaluated as physical function performance tests. Plantar pressure patterns were also examined.
\end{abstract}

Results: Moderate-severe HV (HV angle $\geq 30$ degrees), impaired grip strength and maximum walking speed, and painful HV reduced usual and maximum walking speeds independent of KOA. Hallux plantar pressure decreased according to the $\mathrm{HV}$ angle. Hallux plantar pressure was significantly lower in painful $\mathrm{HV}$ than in the no HV feet or painless HV.

Conclusions: Moderate-severe HV deformity and HV-related pain impaired physical function independent of KOA. By controlling the pain and severe deformity of HV by treatments such as surgery, the physical function of HV patients might be improved.

Keywords: Hallux valgus, Physical function, Knee osteoarthritis, Epidemiology elderly

\section{Background}

Hallux valgus (HV) is one of the most common foot deformities in adults; it is characterized by abnormal angulation, rotation, and lateral deviation of the hallux at the first metatarsophalangeal joint [1]. The prevalence of $\mathrm{HV}$ has been reported as $58 \%$ in adult women and $25 \%$ in adult men ( $\mathrm{HV}$ angle $\geq 15^{\circ}$ ) in the USA [2], 28.4\% in adults (self-reported hallux valgus) in the UK [3], 64.7\% ( $\mathrm{HV}$ angle $\geq 15^{\circ}$ ) in a Korean population aged between 40 and 69 years [4], and $29.8 \%$ ( $\mathrm{HV}$ angle $>20^{\circ}$ ) in a Japanese population aged over 65 years [5]. While HV is basically regarded as a structural deformity, there is debate surrounding the association between abnormal foot structure and related disability. Several studies have

\footnotetext{
* Correspondence: meiten@clin.medic.mie-u.ac.jp

${ }^{1}$ Departments of Orthopaedic Surgery, Mie University Graduate School of Medicine, 2-174 Edobashi, Tsu City, Mie 514-8507, Japan

${ }^{2}$ Departments of Orthopaedic and Sports Medicine, Mie University Graduate

School of Medicine, Tsu City 514-8507, Mie, Japan

Full list of author information is available at the end of the article
}

found no association between HV and disability, such as the Timed Up \& Go test [6], walking speed [6-8], and balance tests [8]. On the other hand, increasing HV severity has been shown to negatively impact health-related quality of life and self-reported function $[4,9,10]$, and HV has been linked to balance function [11] and increased fall risk in older adults $[12,13]$.

Our cohort study started in 1997 to investigate the epidemiology of knee osteoarthritis (KOA) $[14,15]$ and osteoporosis [16]. The study of HV started from 2009, and we reported the prevalence and risk factors for HV [5]. In our study [5], HV showed a significant relationship with KOA. In general, KOA is associated with lower physical extremity function [17]. However, no report has shown a relationship between $\mathrm{HV}$ and physical function after taking into account the existence of KOA.

The purpose of this cross-sectional study was to investigate whether $\mathrm{HV}$ affects physical function after taking into account KOA among elderly persons.

(c) The Author(s). 2018 Open Access This article is distributed under the terms of the Creative Commons Attribution 4.0 International License (http://creativecommons.org/licenses/by/4.0/), which permits unrestricted use, distribution, and reproduction in any medium, provided you give appropriate credit to the original author(s) and the source, provide a link to the Creative Commons license, and indicate if changes were made. The Creative Commons Public Domain Dedication waiver (http://creativecommons.org/publicdomain/zero/1.0/) applies to the data made available in this article, unless otherwise stated. 


\section{Methods}

Individuals aged $\geq 50$ years were recruited from among the inhabitants of a mountain village in Japan. The main industry is the forest industry. The study was started in 1997, with follow-up every two years. All studies were held at the local hospital. This present study analyzed data from the seventh to tenth biennial examinations in 2009, 2011, 2013, and 2015, respectively. The number of participants in 2009, 2011, 2013, and 2015 was 314, 221, 223, and 204, respectively. For individuals who participated in two or more iterations of these four examinations, only the data from the earliest examination were included. For example, if an individual participated in 2009, 2011 and 2015, the data in 2009 were included in this study. Exclusion criteria were rheumatoid arthritis and past history of surgery for hallux valgus. A total of 562 participants (194 male, 368 female) were part of this study.

Before direct examination, a baseline questionnaire including name, age, sex, medical history, and pain was sent to the participants. Direct examination consisted of physical measurement, medical interview, physical examination, X-rays, blood tests, and physical function tests. We measured participants' height and body weight, and the body mass index (BMI) was calculated as weight $(\mathrm{kg}) \mathrm{di}-$ vided by height squared $\left(\mathrm{m}^{2}\right)$. Medical interviews and physical examinations were performed one-on-one by orthopedic surgeons. Bunions were detected by inspection and palpation. Painful bunions were determined by applying pressure to the bunion. Knee X-rays were taken with the knee in a fully extended standing position. KOA was scored according to the Kellgren-Lawrence grading system [18]. Radiographic KOA was defined as grade $\geq 2$. We took foot X-rays with participants standing upright with both feet on the cassette, as described by Saltzman [19]. The HV angle, which is formed by the bone axes of the first metatarsal and the first proximal phalanx, was consistently measured by the same examiner [20]. These imaging data were analyzed using Image J version 1.37 software (National Institutes of Health, Bethesda, MD, USA). Hallux valgus was deemed to be present if the HV angle was $\geq 20^{\circ}$, according to the Japanese Orthopaedic Society criteria. HV severity was classified as mild $\left(\geq 20^{\circ}\right.$ and $\left.<30^{\circ}\right)$, moderate $\left(\geq 30^{\circ}\right.$ and $\left.<40^{\circ}\right)$, or severe $\left(\geq 40^{\circ}\right)$. Participants reporting pain in the right or left hallux on most days of a month for at least 1 month in the previous year were classified as having right or left hallux pain. Participants with radiographic HV and self-reported hallux pain or a painful bunion checked by orthopedic surgeons were defined as having painful HV. If a participant had left hallux pain and right radiographic HV, that participant was not included in the painful HV group.

The physical function tests consisted of grip strength, 6-meter (m) walk at usual and maximum speeds, single-leg stance time with eyes open, and stand up from a chair time. Grip strength was measured using a Takei 5401 handgrip dynamometer (Takei Scientific Instruments Co., Niigata, Japan). The participants stood and held the dynamometer with the arm at right angles and the elbow by the side of the body. Two measurements were done for each hand. We used the average of the highest measurement of each hand. Participants were instructed to walk at their usual and maximum speeds. We measured the time was with a stopwatch. The data for plantar pressure patterns were taken using a gait analyzer (Walk Way MW 1000; Anima, Tokyo, Japan). This analyzer has a sheet length of $2.4 \mathrm{~m}$, and this sheet was set in the middle of the 6-m walkway. In order to investigate how strongly participants pushed the ground with the great toe, the percentage of the hallux footprint in the whole footprint was examined. Each footprint was picked up using the gait analyzer (Fig. 1), and the hallux

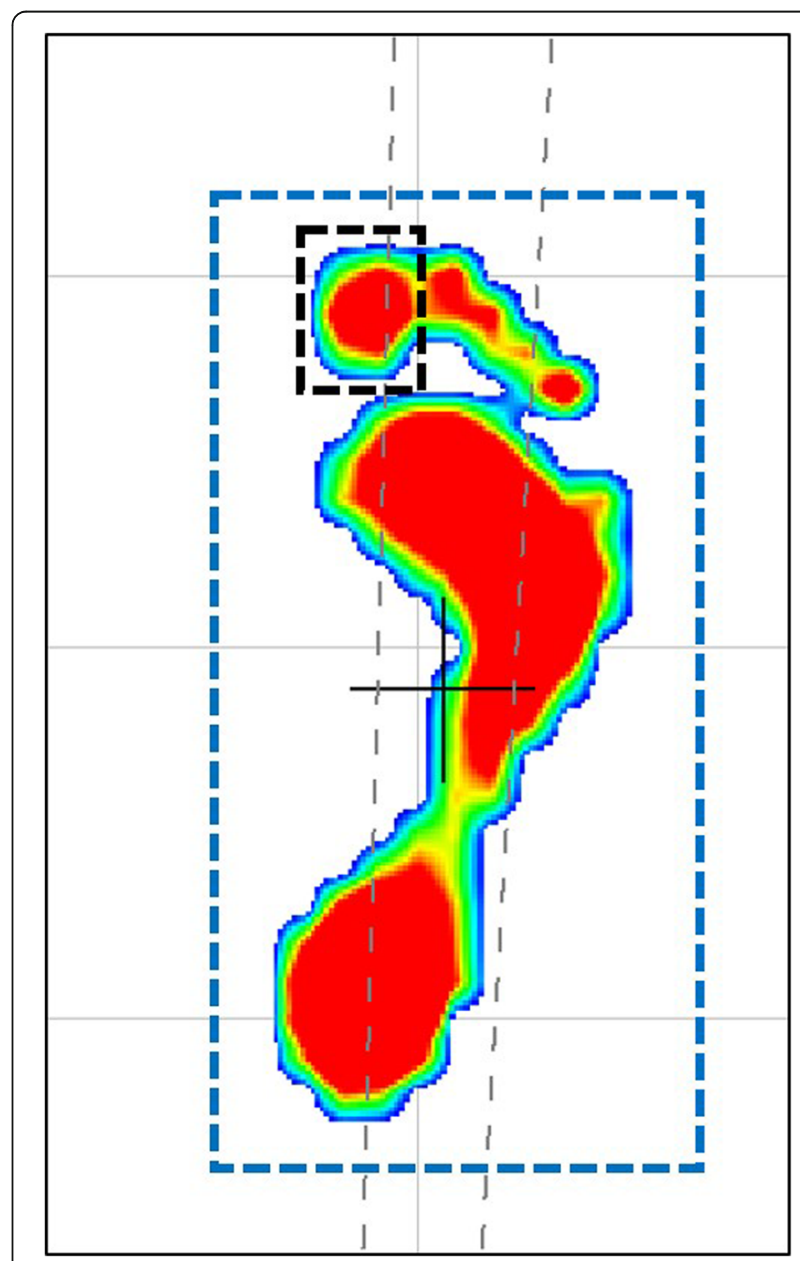

Fig. 1 Representative footprint. Blue dotted line shows the region of interest (ROI) of a whole footprint, and the black dotted line shows the $\mathrm{ROI}$ of a hallux footprint for pressure analysis. The percentage of the hallux footprint is calculated as the hallux footprint pressure divided by the whole footprint 
footprint and the whole footprint were enclosed, and the pressure was analyzed with analysis software (PREDAS MD-1000; Anima, Tokyo, Japan). The percentage of the hallux footprint was defined as [hallux footprint]/[whole footprint]. Examining the foot pressure patterns, the percentage of hallux footprint was checked, from which was calculated hallux pressure/whole foot pressure. We measured single-leg stance time with eyes open for both legs, and we calculated the average time. Participants were instructed to stand on one leg while elevating the contralateral limb. The time until the raised leg was touched on the floor was measured. The maximum time was 60 seconds (s). The stand up from a chair time was the time taken to stand from a chair five times with hands folded in front of the chest and feet flat on the floor.

Based on the worse HV angle in their feet, the participants were classified into a no $\mathrm{HV}$ group ( $\mathrm{HV}$ angle $<20^{\circ}$ ) and an $\mathrm{HV}$ group ( $\mathrm{HV}$ angle $\geq 20^{\circ}$ ). They were then classified into a no $\mathrm{HV}$-mild $\mathrm{HV}$ group ( $\mathrm{HV}$ angle $<30^{\circ}$ ) and a moderate-severe $\mathrm{HV}$ group ( $\mathrm{HV}$ angle $\geq 30^{\circ}$ ). Finally, they were classified into a painful HV group and a no $\mathrm{HV}$ or painless HV group.

\section{Statistical analysis}

Means \pm standard deviations were calculated for variables unless otherwise noted. Associations among the physical characteristics between the groups were determined by the unpaired $t$-test or Fisher's exact test. The relationships between physical functions (grip strength, single-leg stance time, standing up from a chair, and 6-m walking times at usual and maximum speeds) and $\mathrm{HV}$ ( $\mathrm{HV}$ angle $\geq 20^{\circ}$ ), moderate-severe $\mathrm{HV}$ ( $\mathrm{HV}$ angle $\geq 30^{\circ}$ ), or painful $\mathrm{HV}$ ( $\mathrm{HV}$ angle $\geq 20^{\circ}$ with pain) were evaluated by multiple linear regression analysis both after adjusting for age, sex, and BMI, and for age, sex, BMI, and KOA. The correlation between the $\mathrm{HV}$ angle and the percentage of the hallux footprint was analyzed by Pearson's correlation coefficient. Percentages of the hallux footprint between no HV foot and HV, between no HV-mild HV and moderate-severe $\mathrm{HV}$, and between no $\mathrm{HV}$ foot or painless $\mathrm{HV}$ and painful HV were analyzed by the Mann-Whitney test. The significance level was set at $5 \%$ in a two-tailed test. All data were analyzed using PASW Statistics for Windows version 22 (IBM, Armonk, NY, USA).

\section{Results}

The overall prevalence of definite radiographic $\mathrm{HV}$ was $28.4 \%(160 / 562)$; it was $13.4 \%(26 / 194)$ in males and $36.4 \%(134 / 368)$ in females. The rates of mild, moderate, and severe HV in the 562 participants were $16.5 \%$ (93/562), 9.3\% (52/562), and 2.7\% (15/562), respectively.

Table 1 shows the physical characteristics of the participants who fulfilled the criteria. The HV group had
160 participants (26 male, 134 female), whereas the no HV group had 402 participants (168 male, 234 female). Participants in the HV group were significantly shorter and older than those in the no HV group, and the percentages of female and KOA were significantly higher in the $\mathrm{HV}$ group than in the no HV group. When participants were classified into a no $\mathrm{HV}$-mild $\mathrm{HV}$ group and a moderate-severe HV group, participants in the moderate-severe $\mathrm{HV}$ group were significantly shorter and lighter than those in the no HV-mild HV group, and the percentages of female and KOA were significantly higher in the moderate-severe HV group than in the no HV-mild HV group. When participants were classified into a no $\mathrm{HV}$ or painless $\mathrm{HV}$ group and a painful $\mathrm{HV}$ group, the participants in the painful HV group were significantly shorter than those in the no $\mathrm{HV}$ or painless $\mathrm{HV}$ group, and the percentages of female and KOA were significantly higher in the painful $\mathrm{HV}$ group than in the no $\mathrm{HV}$ or painless HV group.

The relationships between $\mathrm{HV}$ and physical functions are shown in Tables 2 and 3. Table 2 shows the results after adjustment for age, sex, and BMI, and Table 3 shows the results after adjustment for age, sex, BMI, and KOA. There was no significant difference between the $\mathrm{HV}$ group and the no HV group in physical functions. On the other hand, grip strength and maximal 6-m walking time were significantly stronger and faster in the no $\mathrm{HV}$-mild HV group than in the moderate-severe $\mathrm{HV}$ group, respectively. In terms of $\mathrm{HV}$-related pain, both usual and maximum walking speeds were significantly slower in the painful HV group than in the no $\mathrm{HV}$ or painless HV group. During 6-m walking, a significant negative correlation was observed between the HV angle and the percentage of hallux footprint (Fig. 2). Pearson's correlation coefficient $(\mathrm{r})$ and the corresponding $p$ value were $r=-0.44$ and $p<0.01$. The percentage of hallux footprint was significantly higher in no HV feet than in HV feet (Fig. 3a). The percentage of hallux footprint was significantly higher in no $\mathrm{HV}$ or mild $\mathrm{HV}$ feet than in moderate-severe HV feet (Fig. 3b). Moreover, the percentage of hallux footprint was significantly higher in no $\mathrm{HV}$ or painless $\mathrm{HV}$ feet than in painful HV feet (Fig. 3c).

\section{Discussion}

The results of this cross-sectional study indicated that participants with moderate-severe $\mathrm{HV}$ or painful $\mathrm{HV}$ had impaired physical functions compared to participants with no $\mathrm{HV}$-mild $\mathrm{HV}$ or painless $\mathrm{HV}$ after taking into account age, sex, BMI, and radiographic KOA. Hallux loading was reduced with increasing HV severity or HV-related pain.

With regard to standing balance, Menz et al. [21], Spink et al. [22], and Nix et al. [11] reported that poorer lateral stability, poorer coordinate stability, and increased 
Table 1 Comparison of participants' basic data between the no HV group and the HV group, between the no HV -mild HV group and the moderate-severe HV group, and between the no HV or painless HV group and the painful HV group

\begin{tabular}{|c|c|c|c|c|c|c|}
\hline & $\begin{array}{l}\text { No HV group } \\
(n=402)\end{array}$ & $\begin{array}{l}\text { HV group } \\
(n=160)\end{array}$ & $\begin{array}{l}\text { No HV-mild HV group } \\
(n=495)\end{array}$ & $\begin{array}{l}\text { Moderate-severe HV group } \\
(n=67)\end{array}$ & $\begin{array}{l}\text { No HV or painless HV group } \\
(n=529)\end{array}$ & $\begin{array}{l}\text { Painful HV group } \\
(n=33)\end{array}$ \\
\hline Age (years) & $* * 71.1 \pm 8.8$ & $73.3 \pm 8.7$ & $71.5 \pm 8.9$ & $73.4 \pm 8.3$ & $71.6 \pm 8.8$ & $74.0 \pm 9.1$ \\
\hline Sex (\% female) & $* * 58.2$ & 83.8 & $* * 62.2$ & 89.6 & $* 64.1$ & 87.9 \\
\hline Height $(\mathrm{cm})$ & $* * 154.6 \pm 8.9$ & $151.1 \pm 7.8$ & $* * 154.2 \pm 8.7$ & $149.7 \pm 7.5$ & ${ }^{*} 153.9 \pm 8.6$ & $148.9 \pm 9.0$ \\
\hline Weight (kg) & $* * 55.8 \pm 10.3$ & $53.5 \pm 9.4$ & $* 55.5 \pm 10.2$ & $52.4 \pm 9.5$ & $55.4 \pm 10.1$ & $51.9 \pm 10.0$ \\
\hline BMI $\left(\mathrm{kg} / \mathrm{m}^{2}\right)$ & $23.3 \pm 3.2$ & $23.4 \pm 3.6$ & $23.3 \pm 3.3$ & $23.4 \pm 3.5$ & $23.3 \pm 3.3$ & $23.4 \pm 3.7$ \\
\hline $\mathrm{KOA}(\%)$ & $* * 33.8$ & 55.0 & $* * 37.2$ & 59.7 & $* 40.0$ & 42.4 \\
\hline
\end{tabular}

$H V$ hallux valgus, $B M I$ body mass index, $K O A$ knee osteoarthritis

${ }^{* *} p<0.01,{ }^{*} p<0.05$

postural sway were associated with HV in elderly populations. On the other hand, Mickle et al. [23] and Menz and Lord [24] showed no relationship between HV and standing balance. These previous reports included much finer analyses, with evaluation of the center of pressure (COP) using a force plate, and/or more severe conditions, such as eyes closed, than the present study. The data of the present study were only for standing time with eyes open to examine standing balance, but there was no relationship between $\mathrm{HV}$ and standing balance. If finer evaluations, such as analyzing COP, and/or more severe conditions, such as eyes closed, were performed, some differences might be detected.

To the best of our knowledge, there have been no reports of the relationship between HV and hand grip strength. The present study showed that moderate-severe HV deformity ( $\mathrm{HV}$ angle $\geq 30^{\circ}$ ) was associated with impaired hand grip strength. It is easy to imagine that patients with moderate-severe HV have smaller grip strength of the foot because of poor alignment of the 1st MTP joint. Grip strength of the hallux might be correlated with hand grip strength. Thus, patients with poor grip strength in the moderate-severe $\mathrm{HV}$ group may show poor grip strength of the hallux. However, this is just a hypothesis, and further studies are needed.

No significant between-group differences were found in walking performance in some studies [11, 22]. The present data for the no HV group and the HV group are consistent with these previous studies. However, the definitions used in the various studies differed, since the data were self-reported (such as the Manchester scale) or $\mathrm{HV}<20^{\circ}$ was used, so that the HV groups had many mild HV participants. In the present study, maximum walking speed was faster in the no HV-mild HV group than in the moderate-severe HV group. Cho et al. [4] showed that participants with moderate or greater HV ( HV angle $>25^{\circ}$ ) had significantly worse functional status, foot health function status, and self-assessment of their foot condition. These data support the present data. There were no data about maximum walking speed in previous studies, but maximum walking requires a higher level of physical function than usual walking. Thus, moderate-severe HV appeared to be associated with maximum walking speed in the present study.

Previous studies reported that foot pain was associated with poor physical function. Some studies [24-26] reported that participants with foot pain had more difficulty walking than participants without foot pain. In addition, some reports $[1,4]$ showed that HV was associated with more self-reported foot pain and poorer self-reported physical function. Abhishek et al. [10] further highlighted the importance of hallux pain with $\mathrm{HV}$, reporting that health-related quality of life was progressively impaired in participants with $\mathrm{HV}$ alone, hallux pain alone, and HV with hallux pain. In the present study, walking speeds of participants with painful HV were slower than those of participants with no HV or mild HV.

Previous reports [27-29] showed an inverse relationship between HV severity and reduced hallux loading. Nix et al. [11] and Mickle et al. [13] showed that participants with $\mathrm{HV}$ had decreased hallux plantar flexion strength. Sanders et al. [30] reported an inverse relationship between $\mathrm{HV}$ angle and hallux plantar flexion strength, as well as lower mean hallux plantar flexion strength in those with painful HV than in those with HV without complaints. Moreover, Mickle et al. [23] reported less hallux loading in HV patients than controls. Hurn et al. [29] reported that participants with moderate (average $\mathrm{HV}$ angle $=30.8^{\circ}$ ) and severe HV (average HV angle $=39.9^{\circ}$ ) showed significantly reduced hallux plantar pressure-time compared to controls. These reports are consistent with the results of the present study. These reduced hallux plantar pressures might reflect impaired physical function, such as slower walking speed.

Caution must be applied when comparing reports from different studies [1]. Some studies have used self-report information, such as the Manchester scale [21-23, 31], and others have used X-ray definitions. In terms of X-ray examinations, studies have used a range of definitions, such as $\mathrm{HV}$ angle $>15^{\circ}$ or $20^{\circ}$ and so 


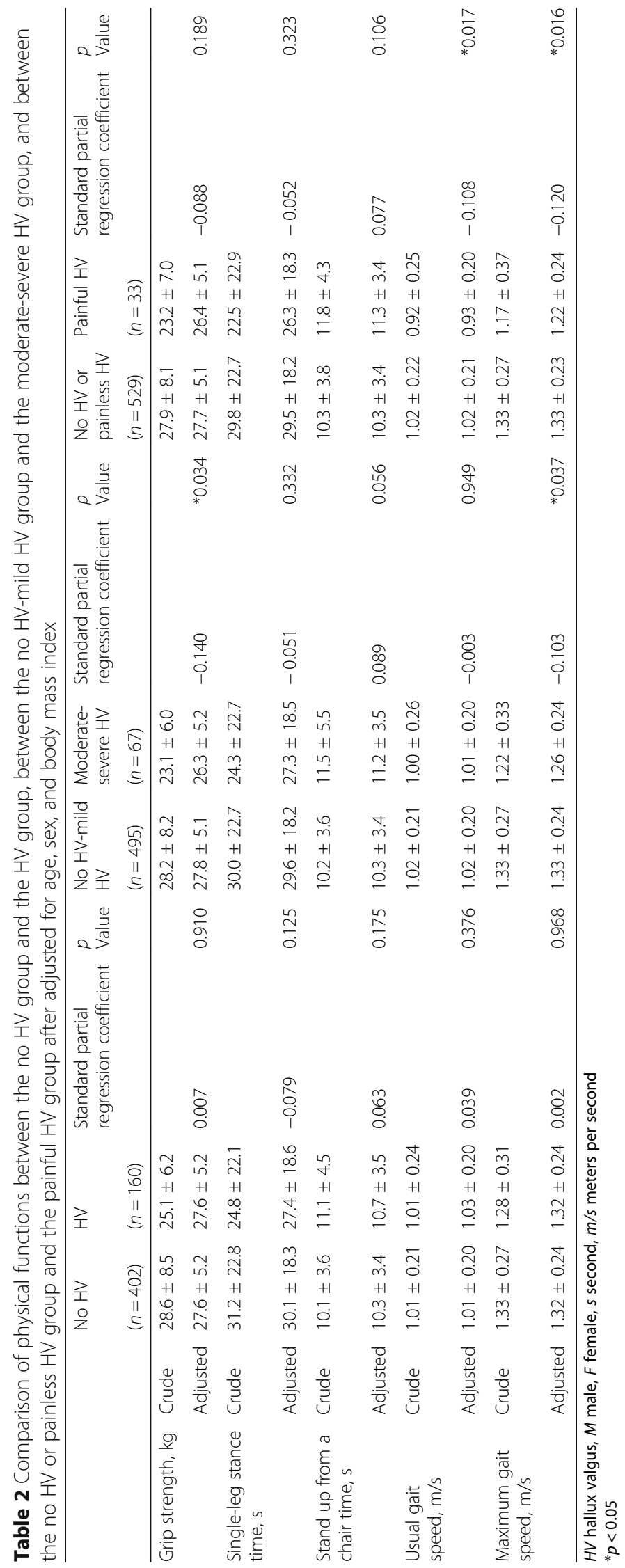




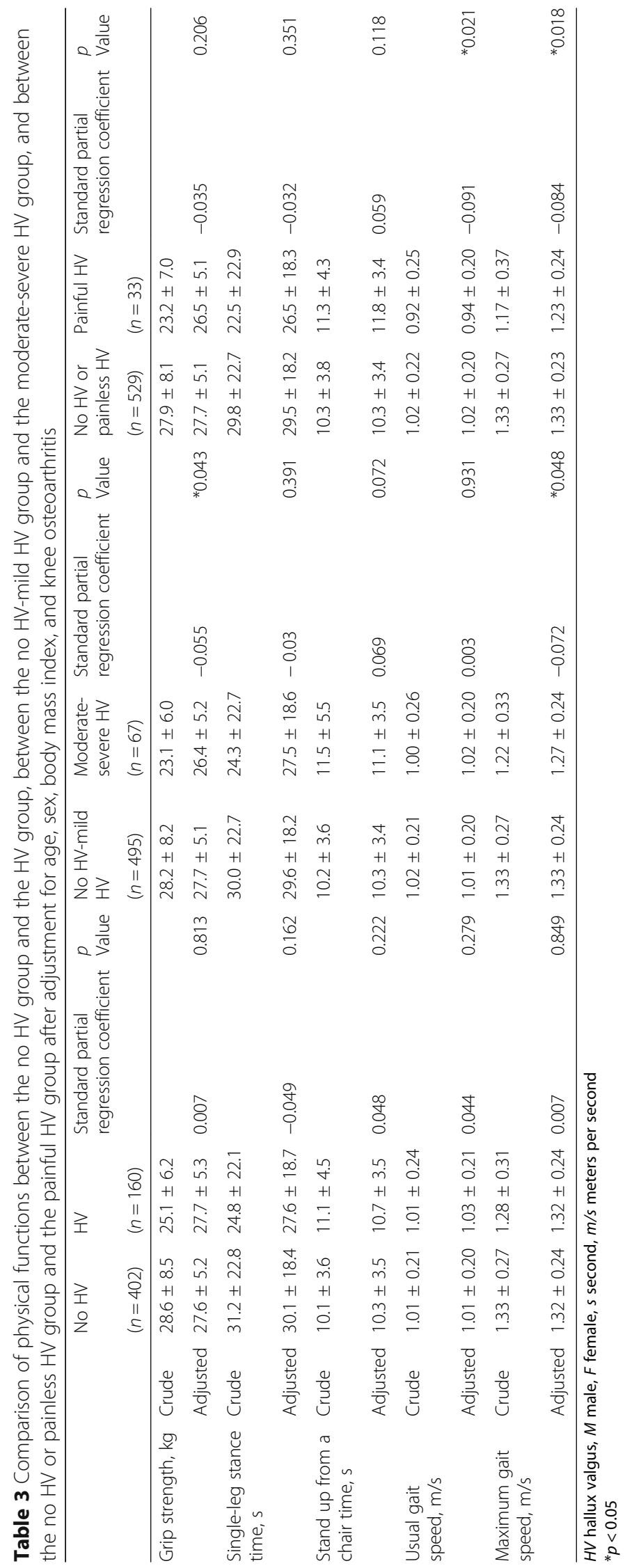




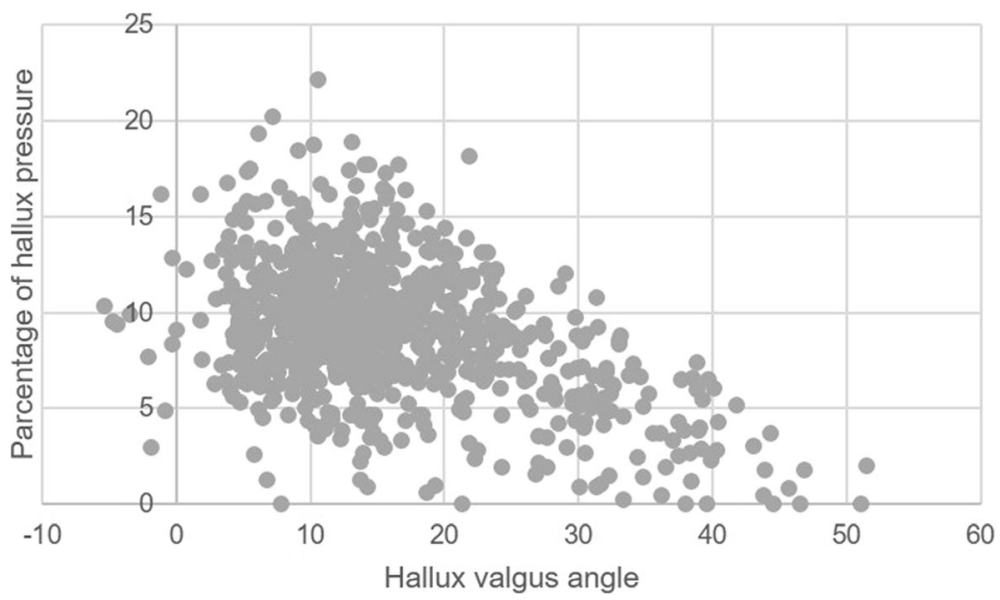

Fig. 2 Relationship between the percentage of hallux footprint and the hallux valgus angle

on. The present study used standardized weight-bearing radiographs, and the definition of $\mathrm{HV}$ was an $\mathrm{HV}$ angle $>20^{\circ}$ according to the definition of the Japanese Foot and Ankle Society.

The present study has several limitations. First, since it was a cross-sectional study, causal relationships cannot be determined. Second, participants could walk to the survey site and could understand and sign an informed consent form. Thus, elderly participants in this study were relatively healthier and had no dementia. Furthermore, since workers in Japan usually retire between 63 and 65 years old, male participants in their 50s usually have health examinations at their work place. Thus, male participants in their 50s who worried about their health

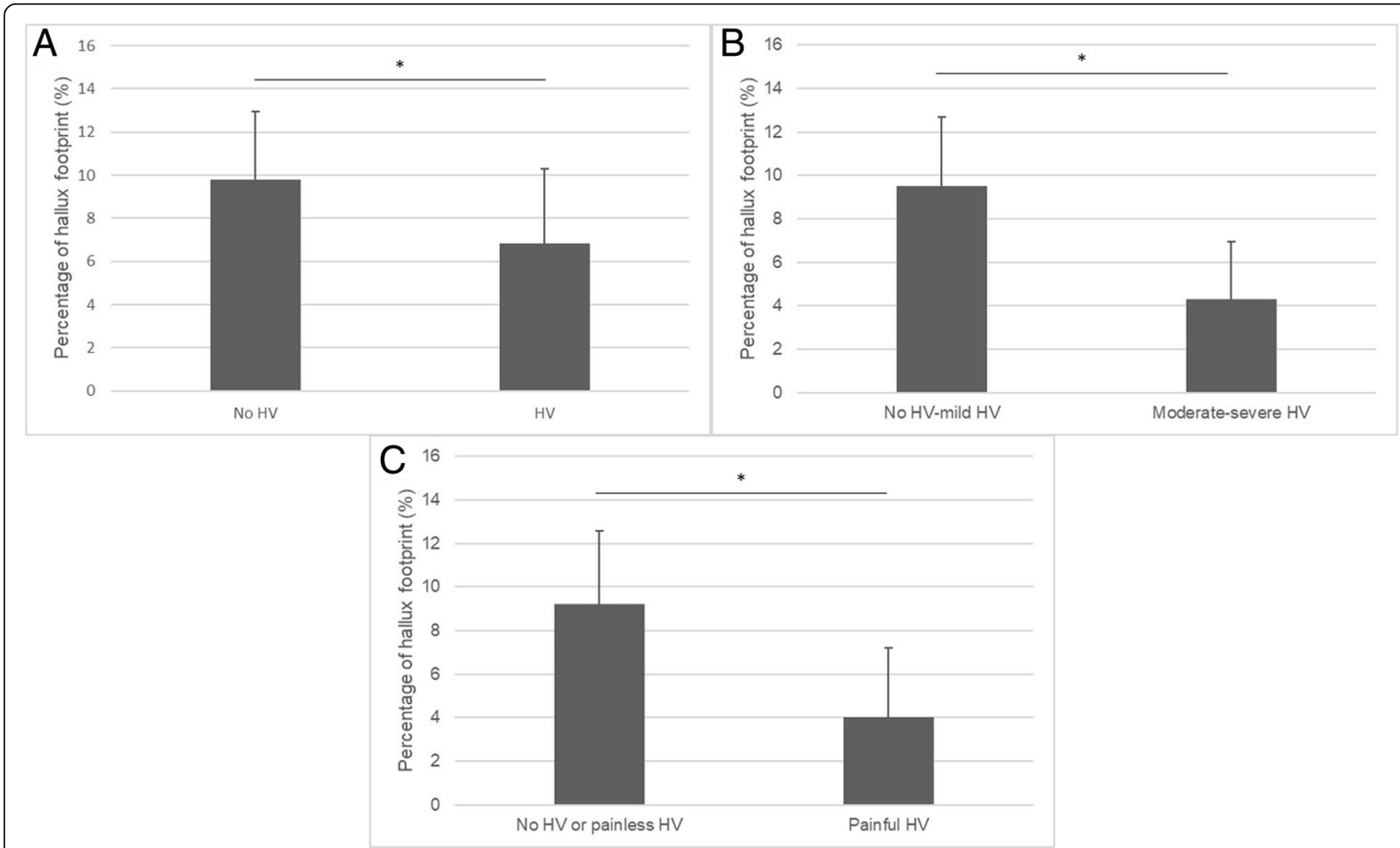

Fig. 3 Comparison of the percentage of the hallux footprint between the no HV group and the HV group (a), between the no HV-mild HV group and the moderate-severe HV group (b), and between the no HV or painless HV group and the painful HV group (c). HV hallux valgus. ${ }^{*} p<0.01$. Mann-Whitney test 
tended to attend our exam. Due to this healthy user bias, the participants in this study do not truly represent the general population. The percentage of men in this study was $34.5 \%$, but the percentage of men over 65 years old in this village was $39.2 \%$ in 2009 . Further, the percentage of men over 65 years old in Japan was $42.8 \%$ in 2009 . This sex mismatch is also one of the limitations. Third, the examinations were held in a specific mountain village, so that this study is not necessarily representative of all of Japan. Fourth, the balance test was simply single-leg standing time with eyes open. If a standing test with eyes closed and/or postural sway using a force plate were used, significant differences might be detected in the balance tests. Fifth, hallux pain is not always due to HV. Thus, painful HV does not necessarily mean pain related to HV.

\section{Conclusions}

This cross-sectional epidemiological study showed that moderate-severe HV impaired some physical functions (grip strength and maximum walking speed), and painful HV slowed walking speed regardless of radiographic KOA. Hallux plantar pressure decreased according to HV angle and pain. We suspect this reduced hallux pressure is one of the reasons for the functional impairments in participants with moderate-severe HV or painful HV. By controlling pain and treating severe HV deformity with treatments such as surgery, the physical functions of HV patients might be improved.

\section{Abbreviations}

BMI: body mass index; HV: hallux valgus; KOA: knee osteoarthritis

\section{Acknowledgements}

The authors would like to thank the staff of Houtoku Hospital for their invaluable assistance.

\section{Funding}

This study was supported by JSPS KAKENHI Grant Number JP15K08732 and Grants-in-Aid for H25-Choujyu-007 (Director, Noriko Yoshimura) from the Ministry of Health, Labour and Welfare of Japan.

\section{Availability of data and materials}

The datasets analyzed during the current study are available from the corresponding author on reasonable request.

\section{Authors' contributions}

AN conceived of this study and participated in the study design, and performed data acquisition, analysis and interpretation, and drafted the manuscript. NI and SN participated in the interpretation of data and performed statistical analyses. KK and AS contributed to the study design and coordination, and helped to draft the manuscript. TO helped to perform statistical analysis and interpretation of data. All authors read and approved the final manuscript.

\section{Ethics approval and consent to participate}

This study was approved by the institutional review board of Mie University Graduate School of Medicine. All of the participants provided written, informed consent.

\section{Competing interests}

The authors declare that they have no competing interests.

\section{Publisher's Note}

Springer Nature remains neutral with regard to jurisdictional claims in published maps and institutional affiliations.

\section{Author details}

'Departments of Orthopaedic Surgery, Mie University Graduate School of Medicine, 2-174 Edobashi, Tsu City, Mie 514-8507, Japan. ${ }^{2}$ Departments of Orthopaedic and Sports Medicine, Mie University Graduate School of Medicine, Tsu City 514-8507, Mie, Japan. ${ }^{3}$ Department of Orthopaedic Surgery, Suzuka Kaisei Hospital, Suzuka City 513-8505, Mie, Japan. ${ }^{4}$ Clinical Research Support Center, Mie University Hospital, 2-174 Edobashi, Tsu City, Mie 514-8507, Japan.

Received: 16 January 2018 Accepted: 17 May 2018

Published online: 29 May 2018

\section{References}

1. Nix S, Smith M, Vicenzino B. Prevalence of hallux valgus in the general population: a systematic review and meta-analysis. J Foot Ankle Res. 2010;3:21.

2. Nguyen US, Hillstrom HJ, Li W, Dufour AB, Kiel DP, Procter-Gray E, Gagnon MM, Hannan MT. Factors associated with hallux valgus in a populationbased study of older women and men: the MOBILIZE Boston study. Osteoarthr Cartil. 2010;18(1):41-6.

3. Roddy E, Zhang W, Doherty M. Prevalence and associations of hallux valqus in a primary care population. Arthritis Rheum. 2008;59(6):857-62.

4. Cho NH, Kim S, Kwon DJ, Kim HA. The prevalence of hallux valgus and its association with foot pain and function in a rural Korean community. J Bone Joint Surg Br. 2009;91(4):494-8.

5. Nishimura A, Kato K, Fukuda A, Nakazora S, Yamada T, Uchida A, Sudo A. Prevalence of hallux valgus and risk factors among Japanese community dwellers. J Orthop Sci. 2014;19(2):257-62.

6. Chaiwanichsiri $D$, Janchai $S$, Tantisiriwat N. Foot disorders and falls in older persons. Gerontology. 2009;55(3):296-302.

7. Badlissi F, Dunn JE, Link CL, Keysor JJ, McKinlay JB, Felson DT. Foot musculoskeletal disorders, pain, and foot-related functional limitation in older persons. J Am Geriatr Soc. 2005;53(6):1029-33.

8. Keysor JJ, Dunn JE, Link CL, Badlissi F, Felson DT. Are foot disorders associated with functional limitation and disability among communitydwelling older adults? J Aging Health. 2005;17(6):734-52.

9. Menz HB, Roddy E, Thomas E, Croft PR. Impact of hallux valgus severity on general and foot-specific health-related quality of life. Arthritis Care Res (Hoboken). 2011;63(3):396-404.

10. Abhishek A, Roddy E, Zhang W, Doherty M. Are hallux valgus and big toe pain associated with impaired quality of life? A cross-sectional study. Osteoarthr Cartil. 2010;18(7):923-6.

11. Nix SE, Vicenzino BT, Smith MD. Foot pain and functional limitation in healthy adults with hallux valgus: a cross-sectional study. BMC Musculoskelet Disord. 2012;13:197.

12. Menz HB, Morris ME, Lord SR. Foot and ankle risk factors for falls in older people: a prospective study. J Gerontol A Biol Sci Med Sci. 2006; $61(8): 866-70$

13. Mickle KJ, Munro BJ, Lord SR, Menz HB, Steele JR. ISB clinical biomechanic award 2009: toe weakness and deformity increase the risk of falls in older people. Clin Biomech (Bristol, Avon). 2009;24(10):787-91.

14. Nishimura A, Hasegawa M, Kato K, Yamada T, Uchida A, Sudo A. Risk factors for the incidence and progression of radiographic osteoarthritis of the knee among Japanese. Int Orthop. 2011;35(6):839-43.

15. Nishimura A, Hasegawa M, Wakabayashi H, Yoshida K, Kato K, Yamada T, Uchida A, Sudo A. Prevalence and characteristics of unilateral knee osteoarthritis in a community sample of elderly Japanese: do fractures around the knee affect the pathogenesis of unilateral knee osteoarthritis? J Orthop Sci. 2012;17(5):556-61.

16. Nishimura A, Akeda K, Kato K, Asanuma K, Yamada T, Uchida A, Sudo A. Osteoporosis, vertebral fractures and mortality in a Japanese rural community. Mod Rheumatol. 2014;24(5):840-3.

17. Iversen MD, Price LL, von Heideken J, Harvey WF, Wang C. Physical examination findings and their relationship with performance-based function in adults with knee osteoarthritis. BMC Musculoskelet Disord. 2016;17:273.

18. Kellgren JH, Lawrence JS. Radiological assessment of osteo-arthrosis. Ann Rheum Dis. 1957;16(4):494-502. 
19. Saltzman CL, Brandser EA, Berbaum KS, DeGnore L, Holmes JR, Katcherian $\mathrm{DA}$, Teasdall RD, Alexander IJ. Reliability of standard foot radiographic measurements. Foot Ankle Int. 1994;15(12):661-5.

20. Helal B, Gupta SK, Gojaseni P. Surgery for adolescent hallux valgus. Acta Orthop Scand. 1974;45(2):271-95.

21. Menz HB, Morris ME, Lord SR. Foot and ankle characteristics associated with impaired balance and functional ability in older people. J Gerontol A Biol Sci Med Sci. 2005;60(12):1546-52.

22. Spink MJ, Fotoohabadi MR, Wee E, Hill KD, Lord SR, Menz HB. Foot and ankle strength, range of motion, posture, and deformity are associated with balance and functional ability in older adults. Arch Phys Med Rehabil. 2011;92(1):68-75.

23. Mickle KJ, Munro BJ, Lord SR, Menz HB, Steele JR. Gait, balance and plantar pressures in older people with toe deformities. Gait Posture. 2011;34(3):347-51.

24. Menz HB, Lord SR. Foot pain impairs balance and functional ability in community-dwelling older people. J Am Podiatr Med Assoc. 2001;91(5):222-9.

25. Leveille SG, Guralnik JM, Ferrucci L, Hirsch R, Simonsick E, Hochberg MC. Foot pain and disability in older women. Am J Epidemiol. 1998;148(7):657-65.

26. Benvenuti F, Ferrucci L, Guralnik JM, Gangemi S, Baroni A. Foot pain and disability in older persons: an epidemiologic survey. J Am Geriatr Soc. 1995;43(5):479-84

27. Menz HB, Morris ME. Clinical determinants of plantar forces and pressures during walking in older people. Gait Posture. 2006;24(2):229-36.

28. Mueller MJ, Hastings M, Commean PK, Smith KE, Pilgram TK, Robertson D, Johnson J. Forefoot structural predictors of plantar pressures during walking in people with diabetes and peripheral neuropathy. J Biomech. 2003;36(7):1009-17.

29. Hurn SE, Vicenzino B, Smith MD. Functional impairments characterizing mild, moderate, and severe hallux valgus. Arthritis Care Res (Hoboken). 2015;67(1):80-8.

30. Sanders AP, Snijders CJ, van Linge B. Medial deviation of the first metatarsal head as a result of flexion forces in hallux valgus. Foot \& ankle. 1992;13(9):515-22.

31. Menz HB, Morris ME. Determinants of disabling foot pain in retirement village residents. J Am Podiatr Med Assoc. 2005;95(6):573-9.

\section{Ready to submit your research? Choose BMC and benefit from:}

- fast, convenient online submission

- thorough peer review by experienced researchers in your field

- rapid publication on acceptance

- support for research data, including large and complex data types

- gold Open Access which fosters wider collaboration and increased citations - maximum visibility for your research: over $100 \mathrm{M}$ website views per year

At BMC, research is always in progress.

Learn more biomedcentral.com/submissions 